\title{
A case of complicated cerebral toxocariasis in a 4-year old child
}

\author{
J. KINČEKOVÁ ${ }^{1}$, P. BÁNOVČIN ${ }^{2}$, M. FEDOR ${ }^{2}$, P. DUBINSKÝ Jr. ${ }^{3}$, H. POLÁČEK ${ }^{4}$, \\ J. PAVLINOVÁ ${ }^{1}$, K. ŠIMEKOVÁ ${ }^{5}$
}

\begin{abstract}
${ }^{1}$ Parasitological Institute, SAS, Hlinkova 3, 04001 Košice, Slovak Republic, E-mail: dr.kincek@zoznam.sk; ${ }^{2}$ Clinic of Pediatrics Diseases of Jessenius Medical Faculty of Komensky University and University Hospital of Martin, Slovak Republic, ${ }^{3}$ East Slovakia Institute of Oncology, Louis Pasteur University Hospital, Košice, Slovak Republic, ${ }^{4}$ Clinic of Radiology Diseases of Jessenius Medical Faculty of Komensky University and University Hospital of Martin, Slovak Republic ${ }^{5}$ Clinic of Infectious Diseases of Jessenius Medical Faculty of Komensky University and University Hospital of Martin, Slovak Republic
\end{abstract}

\begin{abstract}
Summary
We report the case of a 4-year-old boy suffering from a cerebral form of toxocariasis. High serum titres of antiToxocara antibodies indicated that the primary infection was induced by a high number of Toxocara eggs and that the larvae did not penetrate to cerebrospinal fluid due to the hematoencephalic barrier. MRI of the patient's brain showed multiple focal lesions spread diffusely in almost all parts of the brain, predominantly paraventricularly. These might be eosinophil-rich granulomatous infiltrates enclosing larvae. Extensive morphological changes were the cause of serious neurological symptoms, most of them being reversible after follow-up therapy. Radiology proved to be useful diagnostic method, but the specific serological assessment had a key role for the final diagnosis. In conclusion, diagnosis of this patient was intracranial primary Toxocara infection with central quadruparesis and parainfective myocarditis.
\end{abstract}

Key words: cerebral toxocariasis; larval toxocariasis; magnetic resonance; diagnostics

\section{Introduction}

Larval toxocariasis in humans is caused by migrating developmental larval stage of intestinal parasites of dogs (Toxocara. canis) and cats (T. cati). These hosts contaminate the environment with eggs of Toxocara parasites that develop into the infective stage and, under optimal conditions, survive for long period of time (Uga and Kataoka, 1995). Soil in parks, playgrounds and sandpits contaminated with Toxocara embryonated eggs, both in rural and urban areas, represent the main source of human infection (Glickman, 1993).

After ingestion, the eggs hatch in the small intestine, and the larvae immediately invade blood vessels of the intestinal wall to be transported to organs and tissues (Glickman \& Schantz, 1981). In humans, migrating larvae cause different forms of disease depending on the site of invasion and clinical manifestation (Pawlowski, 2001). The asymptomatic form occurs after swallowing a small number of infective eggs or in older infections. The serology provides positive results, but frequently the lack of eosinophilia appears (Bass et al., 1987). Covert toxocariasis with nonspecific symptomatology is a manifestation of local invasion of Toxocara larvae (Taylor et al., 1987). The major form of the disease is visceral larva migrans syndrome (VLM) accompanied with high titres of specific antibodies in serum, increased eosinophilia, hepatosplenomegalia, fever, pulmonary infiltration and other signs. This form is most frequent in juvenile patients (Pawlowski, 2001).

According to Pawlowski (2001), two distinct forms of the disease are distinguishable - the ocular larva migrans (OLM) syndrome and neurological larva migrans (NLM) syndrome which are characterised by specific localisation of larvae (ocular, cerebral). Cerebral localisation has been observed also in other paratenic hosts (e.g. rodents) in dependence on age of infection (Dunsmore et al., 1983; Hrčková \& Velebný, 2001). Clinical signs become evident by a massive number of migrating larvae, whereas the course of mild infection is mostly asymptomatic (Magnawal et al., 1997). This is one reason for the relative rare incidence of the neurological form of toxocariasis in humans of different age (Holland \& Hamilton, 2006).

\section{Case report}

This is the case of four-year-old boy who has been living 
in rural area in a farmer's house with a garden. He used to be in frequent contact with stray cats and dogs.

The boy was admitted to hospital with a history of fever and upper respiratory tract infection two weeks before and a short history of spastic contractions of his legs. Loss of voluntary movement coordination, deterioration of walk and urine incontinence was found on examination.

A CT scan of the brain was performed on admission. Multiple hypodense blurred lesions in fronto-parietal region were found. Subsequently, the boy developed central quadruparesis falling into coma (responding to pain stimuli). Mydriasis was noted when he was transferred to an intensive care unit.

Laboratory reports showed leucocytosis: 24,2 × $10{ }^{9} / 1\left(^{*} 5.5\right.$ - 15,5), eosinophylia: $49 \%(* 0-6 \%)$, high CRP: 9,8 $\mathrm{mg} / \mathrm{l}(*<1)$, higher level of IgG: $22,9 \mathrm{~g} / 1(* 6,9-16,2)$ and $\operatorname{IgM}: 3,1 \mathrm{~g} / 1(* 0,6-2,6)$.

Acute leucaemia was ruled out by cytology and immunophenotypic assessment of bone marrow aspirate. Serology for echinococcosis, cysticercosis, toxoplasmosis, amoebiasis and borreliosis was negative. Biochemistry, cytology and bacteriology of cerebrospinal fluid were negative. An ELISA test was performed as was described previously (Kinčeková et al., 2006) using excretory/secretory antigen from Toxocara canis larvae in a concentration of $5 \mu \mathrm{g}$ proteins/1000 $\mu$ l. Very high levels of IgG antibodies (1: 3200) as well as IgM antibodies (1:1600) were found before treatment with the albendazole and declined during followup the therapy. The same test of cerebrospinal fluid was negative.

EEG was diffusely abnormal with slow delta and theta activity predominantly frontally on both sides. Repolarisation abnormalities on ECG were found. T-troponin level was high $0.55 \mu \mathrm{g} / \mathrm{ml}(*<0.04)$. Echocardiography was normal. This finding was interpreted as compensated parainfection myocarditis. Liver ultrasound showed hepatosplenomegaly with no focal lesions.

Multiple irregular and less defined infiltrates in grey and white matter of the brain were found on MRI. Predominant localization was periventricular and cortical in frontal and occipital regions. The lesions were hypo-intense on T1 weighted image and showed hyper-intense signal on T2 and FLAIR images, where confluent pattern with diameter up to $1-2 \mathrm{~cm}$ was observed (Fig. 1a-b).

The condition was treated by combination of albendazol (400 mg/day) and mebendazol (45 mg/ $\mathrm{kg} /$ day) for 22 weeks and concomitant medication with a cytoprotective drug (trimetazidine hydrochloride, Preductal). The patient underwent subsequent rehabilitation, after which he has improved considerably, although some quadruparesis was still present after 4-weeks.

The patient was evaluated after three months. Follow-up MRI showed $20-25 \%$ remission of brain lesions. Lowgrade central left-sided hemiparesis was found on neurological assessment. There was light residual tricuspidal and pulmonary insufficiency on ECG. Hepatosplenomegaly

* reference values decreased on US examination. Anti-toxocara IgG and IgM antibodies decreased only following several months of intensive antiparasitic therapy (Fig. 2).
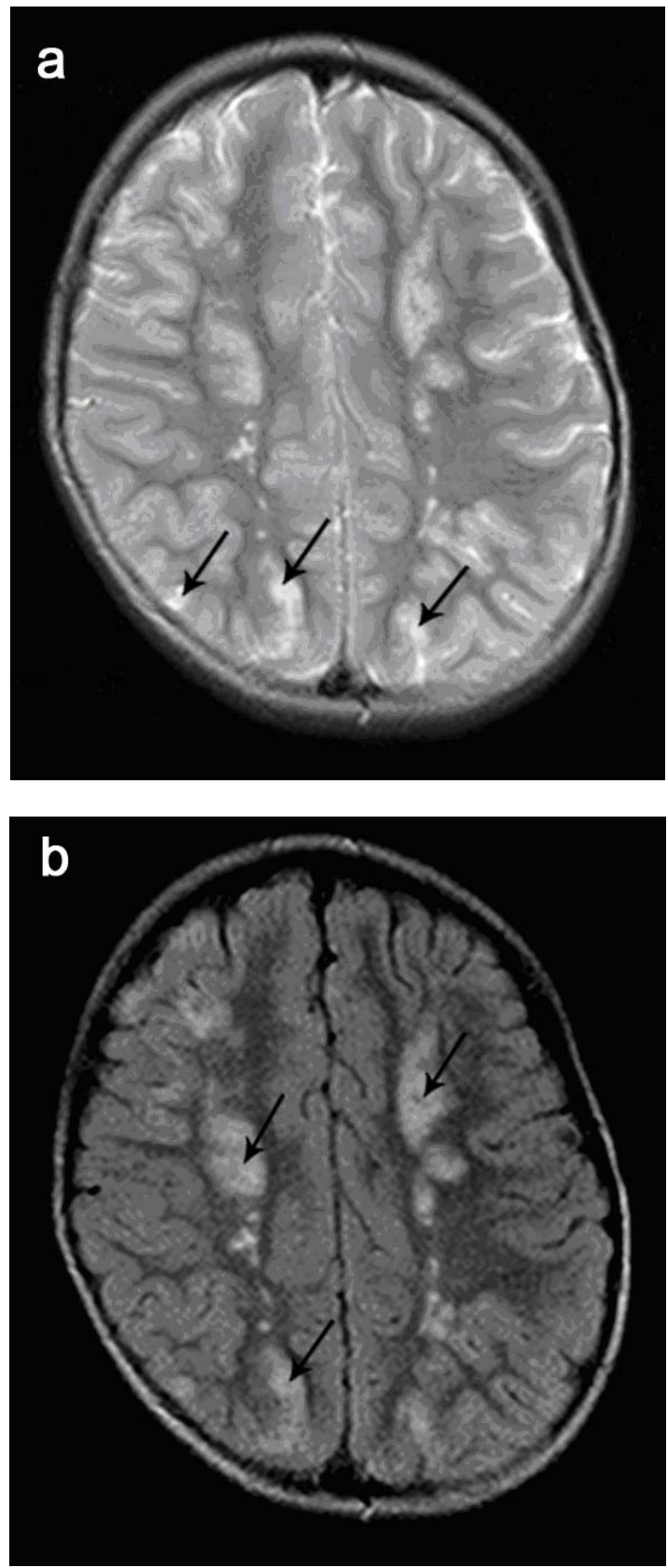

Fig 1. Diffuse, confluent hyper-intense brain lesions were found in both gray and white matter. a - MRI T2 weighted sequences; b - FLAIR weighted sequences.

\section{Discussion}

Cerebral Toxocara infections in humans are rare and the clinical pattern of neurotoxocariasis may be that of eosinophylic meningitis, encephalitis, myelitis, seizures, vasculitis or isolated behavioral changes (Vidal et al., 2003; Marx et al., 2007). A young woman diagnosed for neurotoxocariasis (Mizuki et al., 1985) suffered from se- 


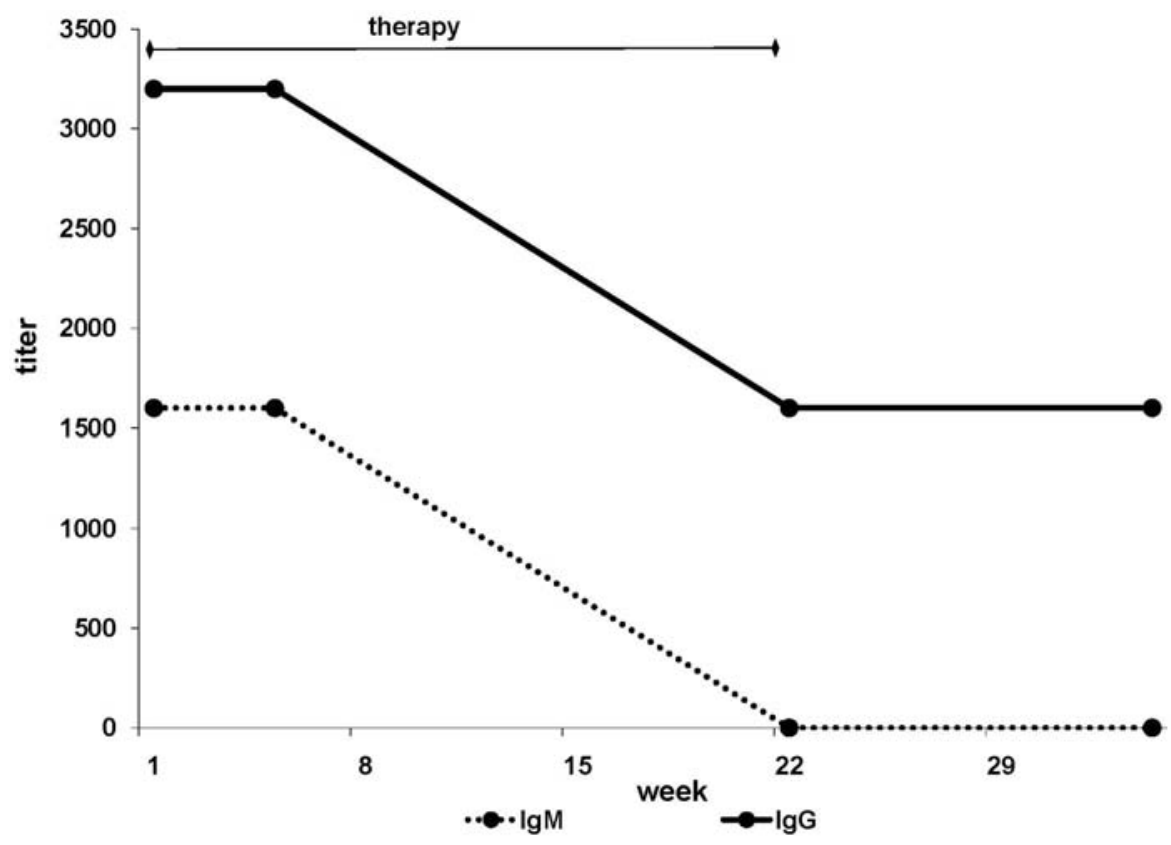

Fig.2. Titres of anti-Toxocara IgG and IgM antibodies during drug administration and follow-up therapy.

vere eosinophylic meningitis and the authors suggested that the serious course of the disease was due to the immunodeficiency caused by parallel rubella infection. Accumulation of a large number of larvae in a brain occurs probably only after high inoculation dose with embryonated Toxocara eggs (Glickman \& Schantz, 1981). This seems to be also the case in our patient as MRI showed multiple focal lesions spread diffusely in almost all parts of the brain, predominantly paraventricularly. In addition, high titres of specific IgG and $\operatorname{IgM}$ antibodies in serum are also an indication of intense primary infection. The strong correlation between antibody levels to the larval excretory/secretory antigens and infection dose was demonstrated experimentally (Havasiová-Reiterová et al., 1995). However, there was a negative serological response in cerebrospinal fluid, suggesting that larvae did not penetrate to the brain cavities probably due to the haematoencephalic barrier. Eosinophil blood counts are highly elevated in majority of patients having high IgG titres, but in the case of ocular toxocariasis, eosinophilia is present only in $10-15 \%$ of patients (Gillespie et al., 1993). Only very rarely eosinophilia can be found in the cerebrospinal fluid (Vidal et al., 2003). MRI examination of our patient revealed multifocal hypo-intense lesions on T1 weighted image and hyper-intense signal on T2 type of images, where confluent pattern with diameter up to $1-2 \mathrm{~cm}$ was observed. Extensive morphological changes seem to be the cause of serious neurological symptoms (Holland \& Hamilton, 2006) observed in the patient and most of them disappeared or diminished during follow-up the therapy. Brain lesions represent the host immune response to the presence of Toxocara larvae antigens and in the brains of experimentally infected animals inflammatory lesions comprise mainly of T-lymphocytes, glial cells and minor number of eosinophils (Hrčková, 2006). This is in contrast with other infected organs (liver and lungs), where eosinophils are the dominant cell type in granulomas. It is interesting, that parasite-induced lesions were found predominately in the white matter of brain and cerebellum (Xinou et al., 2003). In some cases of neurotoxocariasis, MRI examination shows vasculitis, which could result in the frequent brain strokes (Marx et al., 2007). In our patient, neurological symptoms were multiple and variable indicating quite extensive morphological changes of brain tissue. In severe Toxocara infections in humans, myocarditis could be another pathological complication and it was described in $10-15 \%$ of patients with visceral form of disease Kohtaro et al., 2002). Heart tissue damage is caused by the enzyme peroxidase released from infiltrated eosinophils (Dimayuga et al., 1991), regardless of the presence or absence of larvae. In our patient EKG examination showed re-polarized changes and arythmia and serum troponine levels were also significantly elevated, therefore specific treatment was added to antiparasitic therapy. Other examinations did not show pathological changes of the heart. Treatment of patients with severe Toxocara infection requires long-lasting administration of anthelmintic drugs of which benzimidazole carbamates are the most effective (Magnaval, 1994). However, the effect of therapy can be assessed indirectly, from diminishing clinical symptoms and serological parameters. After four weeks of drug administration, both IgG and IgM antibody levels declined gradually within six months of follow-up. Middle titres of IgG antibodies persisted, although eosinophilia dropped down and myocarditis improved. We conclude that in case of rare cerebral toxocariasis, definitive diagnosis can hardly be found from the patient's nonspecific neurological symptoms and radiodiagnostic (MRI, CT) examinations. This is only possible after serological examination of serum and/or cerebrospinal fluid for the presence of specific antitoxocara antibodies. 


\section{Acknowledgement}

The work was supported by the Science Grant Agency VEGA 2/7186/27 and the Slovak Research and Development Agency under the contract No. APVV- 51-027605.

\section{References}

Bass, J. L., Mehta, K. A., Glickman, L. T., Blocker, R., EPPES, B. M. (1987): Asymptomatic toxocariasis in children. Clin. Pediatr. Hagerstown, 26: $441-446$

Dimayuga, E., Stober, M., Kayes, S. G. (1991): Eosinophil peroxidase levels in hearts and lungs of mice infected with Toxocara canis. J. Parasitol., 77: 461 - 466

Dunsmore, J. D., Thompson, R. C. A., BAtes, I. A. (1983): The accumulation of Toxocara canis larvae in the brains of mice. Int. J. Parasitol., 13: 517 - 521

Gillespie, S., DinNig, W. J., Voller, A., CrowCroft, N. S. (1993): The spectrum of ocular toxocariasis. Eye, 7: 415 $-418$

Glickman, L. T. (1993): The epidemiology of human toxocacariasis. In LEVIS, J.W. and MAIZELS, R. M. (Eds.): Toxocara and Toxocariasis Clinical, Epidemiologycal and Molecular Perspectives. Institute of Biology, London, 3-10 GlickMan, L. T., Schantz, D. M. (1981): Epidemiology and pathogenesis of zoonotic toxocariasis. Epidemiol. Rev., 3: $230-250$

HAVASIOVÁ - REITEROVÁ, K., TOMAŠOVIČOVÁ, O., DUBINSKÝ, P. (1995): Effect of various doses of infective Toxocara canis and Toxocara cati eggs on the humoral response and distribution of larvae in mice. Parasitol. Res., 81: $13-17$

Holland, C. V., Hamilton, C. (2006): The significance of cerebral Toxocariasis. In Holland C. V., SMITH, H. V. (Eds): Toxocara: the enigmatic parasite. CABI Publishing, Wallingford, pp. $58-73$

HRČKOVÁ, G., VELEBNÝ, S. (2001): Treatment of Toxocara canis infections in mice with liposome-entrapped benzimidazole carbamates and immunomodulator glucan. J. Helminthol., 75: $141-146$

HRČKOVÁ, G. (2006): Novel approaches to immunoprophylaxis for toxocariasis. In Holland, C.V. and SMITH, H.V. (Eds): Toxocara: the enigmatic parasite. CABI Publishing, Wallingford, pp. $174-194$
KinČEKovÁ, J., ReITERovÁ, K., Dubinský, P. (1999): Larval toxocarosis and its clinical manifestation in childhood. J. Helminthol., 73: 323 - 328

KinČEKOVÁ, J., HrČKOVÁ, G., Auer, H., SzIlÁGyiovÁ, M., HudačKová, J., Stanislayová, M., PolÁČeK, H., ŠIMEKOVÁ, K. (2006): Clinical and serological study of human alveolar echinococcosis in Slovakia in relation to the outcome of chemotherapy. Helminthologia, 43: $213-$ 219

Kohtaro, A., Shimokawa, H., Kubota, T., NawA, Y., TAKeshitA, A. (2002): Myocarditis associated with visceral larva migrans due to Toxocara canis. Intern. Med., 41: $706-708$

MagnaVAl J. F. (1994): Comparative efficacy of diethylcarbamazine and mebendazole for the treatment of human toxocariasis. Parasitology, 110: $529-533$

Magnaval, J. F., Galindo, V., Glickman, L. T., ClaNET, M. (1997): Human Toxocara infection of the central nervosus system and neurological disordes: a case-control study. Parasitology, 115, 537 - 543

MarX, C., Masruha, M. R., Rodrigues, M. G., DA Rocha, A. J., Vilanova, L. C. P., Gabbai, A. A. (2007): Toxocariasis of the simulating acute disseminated encephalomyelitis. Neurology, 69: $806-807$

Mizuki, M., NaKazato, O., Nagamatsu, T., OKaJima, T. (1985): A case of eosinophilic meningitis. Clin. Neurol., 25: $674-679$

PAWLOWSKI, Z. (2001): Toxocariasis in humans: clinical expression and treatment dilemma. J. Helminthol., 75: 299 $-305$

TAYlOR, M. R., KeANE, C. T., O’ CONNOR, P., GIRDWOOD, R. W., SMith, H. (1987): Clinical features of covert toxocariasis. Scand. J. Infect. Dis., 19: 693 - 696

Uga, S., KATAOKA, N. (1995): Measures to control Toxocara egg contamination in sandpits of public parks. Am. J. of Trop. Med. and Hyg., 52: $21-24$

Vidal, J. E., SzTajnBoK, J., Seguro, A. C. (2003): Eosinophilic meningoencephalitis due to Toxocara canis: case report and rewiew of the literature. Am. J. Trop. Med. Hyg., 69: $314-343$

Xinou, E., LefKopoulos, A., Gelagoti, M., Drevelegas, A., Diakou, A., Milonas, I., Dimitriadis, A.S. (2003): CT and MR imaging findings in cerebral toxocaral disease. Am. J. Neuroradiol., 24: $714-718$ 